\title{
Evaluation for Pollution Characteristics of Sincheon River and its Tributaries South Korea
}

\author{
Yeong-Geum Son, Heung-Bin Im, Kang-Hyuck Lee, Jin-Guil Kim, Yun-Jung Lim, Jeong-in Choi, \\ Ho-jung Lee, Jo-Gyo Oh \\ Gyeonggi Province Institute of Health \& Environment \\ 1 Cheongsa-ro, Uijeongbu-si, Gyeonggi-do, 480-764, South Korea \\ whfflsgkfn@naver.com
}

\section{Extended Abstract}

The objective of this study is to analyze Sincheon basin water environment system in republic of Korea. The data were collected from 2010 August to 2016 December [1] including BOD, SS, T-N, T-P[2]. The Sincheon water system includes 15 tributaries such as BS, DG, SW, HC and SP stream. The results were as followed that the inflow of HC, SW and SP induced the increasing the pollution degree of BOD and T-N level for Sincheon river. Pollution degree of tributaries were higher than main stream of Sincheon [3].

The main reason of pollution of Suk-Woo was untreated wastewater, and it influenced downstream of SW. HC stream satisfied the water quality standard [4] [5], but $\mathrm{Zn}$ was designated as a monitoring contaminants, was high at 14.67 $\mathrm{mg} / \mathrm{L}$ (standard $0.02 \sim 2.45 \mathrm{mg} / \mathrm{L}$ )because of textile wastewater. SP stream was polluted by livestock wastewater of as nonpoint source. Ecological toxicity of BS and DG were higher than other tributaries. Ecological toxicity experiment used water fleas called daphnia magna. Daphnia magna was influenced by $\mathrm{Cr}^{6+}$ of metal plating wastewater in DG.

In order to recover the Sincheon water system, it is necessary to manage textile, livestock and metal plating wastewater.

\section{References}

[1] Ministry of Environment, Water information system, [Online]. Available: http://water.nier.go.kr/waterMeasurement/ selectWater.do

[2] Ministry of Environment, Water quality test method enacted by Korean Ministry of Environment, 2016.

[3] J. D. Park, J. L. Kim, D. H. Phew, D. I. Jung, "A Study on the Water Quality Patterns of Unit Watersheds for the Management of TMDLs -in Nakdong River Basin,” J. Korean Society on Water Environment., vol. 26, no. 2, pp. 279- 288, 2010.

[4] O. Y. Choi, K. H. Kim and I. S. Han, "A Study on the spatial strength and cluster analysis at the unit watershed for the management of total maximum daily loads," J. Korean Society on Water Environment., vol. 31, no. 6, pp. 700701, 2015.

[5] J. H. Park, M. J. Moon., H. J. Lee, K. S. Kim, "A Study on characteristics of water quality using multivariate analysis in Sumjin river basin," J. Korean Society on Water Environment., vol. 30, no. 2, pp. 119-127, 2014. 